\title{
Preschool Predictors of Reading Ability in the First Year of Schooling in Children With ASD
}

\author{
Marleen F. Westerveld (D), Jessica Paynter (D), Kathryn O’Leary, and David Trembath
}

\begin{abstract}
A high percentage of children with Autism Spectrum Disorder (ASD) show elevated challenges in learning to read. We investigated longitudinal predictors of reading skills in 41 children diagnosed with ASD. All children completed measures of precursor literacy skills at the age of 4-5 years, including phonological awareness, letter sound knowledge, rapid automatic naming, name writing, and phonological memory (digit span), along with measures of word- and passage-level reading skills in their first year of formal schooling. Nonverbal cognition and letter sound knowledge accounted for $53.4 \%$ of the variance in regular single word reading at school age, with letter sound knowledge a significant individual predictor. Overall, 18 children showed reading ability scores in the average range on a standardized test of passage-level reading ability, whereas 23 children performed below expectations. These groups differed significantly on all precursor literacy measures (at ages 4-5), except autism symptoms based on parent report. Group membership was significantly predicted by preschool receptive vocabulary, name writing, and rapid automatic naming, with high sensitivity and specificity. These results are discussed in reference to the literature describing early literacy predictors for typically developing children, highlighting key areas for future intervention and support. Autism Res 2018, 11: 1332-1344. (C) 2018 International Society for Autism Research, Wiley Periodicals, Inc.
\end{abstract}

Lay summary: Children with autism are at increased risk of persistent reading difficulties. We examined whether preschool reading-related skills linked to later reading ability. Performance on the following three tasks administered at preschool predicted children who showed early reading success versus below expectations in their first year of school: vocabulary, name writing, and rapid naming of familiar objects and shapes. These results can inform future interventions.

Keywords: emergent literacy; autism; preschool; longitudinal; reading; decoding

\section{Introduction}

Early reading success is a significant predictor of longterm reading ability [Sparks, Patton, \& Murdoch, 2014], underpinning academic achievement and future occupational attainment. The early years of schooling are often referred to as the "learning to read" stage [Chall, 1983], during which time children learn to read words accurately and fluently and to decode unfamiliar words. Generally around year four of schooling, most children have become skillful in reading both familiar and unfamiliar words; at that stage, the emphasis at school shifts to "learning through reading." Unfortunately, many children experience difficulties learning to read, including a large proportion of children with Autism Spectrum Disorder (ASD) [Brown, Oram-Cardy, \& Johnson, 2013; Henderson, Clarke, \& Snowling, 2014].
The focus of this study is on identifying factors that predict early reading ability in children with ASD, with the view to address the needs of those with difficulties. Although previous research suggests children with ASD as a group demonstrate relative strengths in reading ability (i.e., to read accurately at word and passage level) [Huemer \& Mann, 2010; Nation, Clarke, Wright, \& Williams, 2006], closer inspection of the reading skills of young children with ASD uncovers not only a wide range in performance but also reveals $50 \%$ of individual children struggling with reading accuracy, with some children unable to read at all [e.g., Nation et al., 2006]. To better understand these challenges, some children with ASD experience in achieving early reading success, the current longitudinal study investigated the reading accuracy skills of children with ASD who were in their first year of formal schooling and who were initially assessed prior to school entry [Westerveld et al., 2017].

From the Griffith Institute for Educational Research, Griffith University, Brisbane, Queenland, Australia (M.F.w.); Cooperative Research Centre for Living with Autism, Brisbane, Queenland, Australia (M.F.w., J.P., K.o.L., D.T.); Menzies Health Institute Queensland, Gold Coast, Queensland, Australia (M.F.W., J.P., D.T.);

Received October 17, 2017; accepted for publication June 10, 2018

Address for correspondence and reprints: Marleen Westerveld, School of Allied Health Sciences, Griffith University, Griffith Health Centre G40 2.70, Queensland, 4222, m.westerveld@griffith.edu.au

Published online 26 August 2018 in Wiley Online Library (wileyonlinelibrary.com)

DOI: 10.1002/aur.1999

(C) 2018 International Society for Autism Research, Wiley Periodicals, Inc. 


\section{Predictors of Early Reading Ability in Typically Developing Children}

Predictors of proficient reading accuracy skills in typically developing populations, also referred to as precursor, or emergent literacy skills [National Early Literacy Panel, 2008], are well established, and include phonological awareness (PA), alphabet knowledge (including letter sound knowledge [LSK]), rapid automatic naming (RAN), name writing, and phonological memory (p. vii). PA refers to the conscious awareness of the phonological structure of spoken words [Gillon, 2018] and is evidenced by children's ability to identify and manipulate phonemes (sounds) in words (e.g., identifying the first phoneme, blending phonemes to form a word). Together with LSK, PA enables children to map phonemes in spoken language to written words. Phonological memory refers to the ability to remember spoken information for a short amount of time and assists in temporarily holding "decoded information" before blending the phonemes into words [Wagner \& Torgesen, 1987]. RAN refers to the speed with which an individual can name, for example, familiar pictures and requires efficient retrieval of phonological codes from longterm memory. It is hypothesized that both naming of pictures and reading involve lexical retrieval of familiar phonological sequences; in support, children with specific wordlevel reading problems have been found to show significantly poorer performance on RAN tasks than children without [Bishop, McDonald, Bird, \& Hayiou-Thomas, 2009]. Finally, early name writing is hypothesized to be linked to children's developing knowledge of print concepts (i.e., reading from left to right, identifying letters and words in books) and alphabet knowledge [Cabell, Justice, Zucker, \& McGinty, 2009] and shows a predictive relationship with early spelling attempts one year later [e.g., McNeill, Westerveld, Bysterveldt, Boyd, \& Gillon, 2013].

\section{Reading Skills of Children With ASD}

Research into the reading skills of children with ASD has gained momentum in the last decade [e.g., Arciuli, Stevens, Trembath, \& Simpson, 2013; Davidson \& Ellis Weismer, 2014; Jacobs \& Richdale, 2013; McIntyre, Solari, Grimm, Lerro, Gonzales, \& Mundy, 2017; Nation et al., 2006; Wei, Christiano, Yu, Wagner, \& Spiker, 2015]. These studies have predominantly focused on describing reading profiles, mainly in high-functioning (IQ > 70) school-age children with ASD. Most of these studies showed a high incidence of reading difficulties in clinical samples, ranging from $29 \%$ to $42 \%$, with specific challenges in reading comprehension (ranging from 53\% to 65\%). Closer inspection of these studies' results, however, reveals that a significant proportion of the participants achieved below expectations in reading accuracy, measured using word-level reading tasks or passage reading tasks [Arciuli et al., 2013; Nation et al., 2006]. Arciuli et al. [2013], for example, reported that 39\% of their participants, ranging in age from 6 to 11 years, scored $<1$ SD on a test of passage-level reading accuracy. More recently, McIntyre, Solari, Grimm, et al. [2017] in their examination of reading profiles of 81 students with high-functioning ASD (IQ > 75, ages 8-16 years) showed that as a group, performance on three measures of word recognition (nonword reading, sight word reading, and text-level reading accuracy) was within normal limits (mean standard scores [SSs] 95 and 93 and scaled score of 8 , respectively), but variability in performance was high, from severely impaired to above expectations on all measures. In a companion paper, the authors reported that $21 \%$ of their sample performed significantly below age expectations in single word reading involving a combination of sight words and nonwords [McIntyre et al., 2017], and also noted significant difficulties in passage reading accuracy in this group of school-age students with ASD compared to their peers with attention-deficit/hyperactivity disorder and their typically developing peers. Taken together, the results from these studies indicate that the group-level findings that children with ASD show relative strengths on tasks measuring word- or passage-level reading accuracy may mask the significant reading accuracy challenges many individual children with ASD demonstrate.

Potential reasons for this variability in reading accuracy performance within groups of children with ASD may be related to their oral language skills, their nonverbal cognitive abilities, and/or autism severity [Davidson \& Ellis Weismer, 2014; Lindgren, Folstein, Tomblin, \& TagerFlusberg, 2009; McIntyre, Solari, Grimm, et al., 2017; Norbury \& Nation, 2011]. In support, there is evidence to suggest that children with ASD who show intact structural language skills on the Clinical Evaluation of Language Fundamentals (CELF)_3rd Edition (Language Normal [LN] group) perform significantly better on reading accuracy tasks than their peers with ASD and additional language impairment (Language Impaired [LI] group) [Lindgren et al., 2009]. It should be noted that the children with ASD in the LN group outperformed their LI peers on measures of nonverbal cognition, so it is not clear if word reading difficulties can be attributed to the children's structural language impairment or to their intellectual functioning, or both.

McIntyre, Solari, Grimm, et al. [2017] assessed 81 highfunctioning (IQ $\geq 75$ ) children (ages 8-16) with ASD and found a significant association between autism severity and a "severe global disturbance" profile (14\% of the sample). This group of participants demonstrated higher levels of autism symptomatology and performed poorly on all language and reading variables, including sight word recognition, text reading accuracy, and RAN. In summary, evidence suggests that there is no single reading profile that is typical for school-age children with 
ASD [Norbury \& Nation, 2011]. A better understanding of these children's early reading trajectories may assist in providing targeted reading instruction during the early years of schooling.

\section{Predictors of Early Word Reading Skills in Children With ASD}

Only three studies have investigated the concurrent or longitudinal predictors of early word reading skills in children with ASD [Davidson \& Ellis Weismer, 2014; Dynia, Brock, Justice, \& Kaderavek, 2017; Jacobs \& Richdale, 2013]. Investigating the emergent literacy skills of children with ASD prior to school entry is important to control for the positive influence formal reading tuition has on early literacy performance. One example is a recent study by Dynia et al. [2017], who investigated the links between preschool performance on measures of oral language, alphabet knowledge (letter name knowledge), print-concept knowledge and PA, and children's performance on a task measuring nonword reading skills 1 year later. Two groups of children participated, a group of children with ASD $(n=25)$ and their peers with typical development $(n=66)$. Although there was some evidence of the predictive validity of preschool PA on later decoding ability, the contribution was minor (4\%). There are several limitations to this study that may significantly hinder the interpretation of the results, including a small sample size $(n=25)$ and attrition $(29 \%)$, and it is not clear the extent to which this group reflected the original participant group. Furthermore, a nonword reading task was used as the only outcome measure of decoding (with a high percentage of missing data and possible floor effects). Moreover, several important predictor variables were not taken into account, such as nonverbal cognition, phonological memory, or RAN [Davidson \& Ellis Weismer, 2014; Fricke, Szczerbinski, Fox-Boyer, \& Stackhouse, 2016; National Early Literacy Panel, 2008]. To illustrate, Davidson and Ellis Weismer [2014] found significant concurrent correlations between nonverbal cognition, oral language skills, and autism severity and children's performance on the Test of Early Reading Ability-3rd edition (TERA-3) [Reid, Hresko, \& Hammill, 2001] in a group of 94 children with ASD (ages 4 years, 9 months to 6 years, 7 months), some of whom had started their first year of formal schooling.

\section{The Current Study}

The current study builds on previous research by evaluating the links between preschool precursor literacy skills and reading accuracy abilities in a group of children with ASD who were in their first year of schooling. It extends previous research in several ways. First, it used a more comprehensive battery of emergent literacy tasks to include the five main predictors of early reading performance established in previous research, that is, PA, alphabet knowledge (LSK), RAN, name writing, and phonological memory [National Early Literacy Panel, 2008]. Second, at Time 1, none of the children had commenced formal schooling, therefore controlling for possible schooling effects. Third, all children in our study had a confirmed diagnosis of ASD. For this study, the reading accuracy skills (at word level and passage level) of this group of children with ASD will be described. The following research questions were asked: (a) Do nonverbal cognition, oral language, and precursor literacy skills at preschool predict single word reading ability in the first year of formal schooling? (b) Do preschool nonverbal cognition, oral language, and precursor literacy skills differ between average or below average readers (based on a standardized test measuring passage-level reading ability) in year one of schooling? And (c) Do preschool oral language and precursor literacy performance predict whether students will be average or below average readers in their first year of formal schooling?

Based on previous research findings, we anticipated a wide range in reading performance in our sample of school-age students with ASD [Davidson \& Ellis Weismer, 2014; Dynia et al., 2017]. Similar to typically developing children and children with identified language disorders, we expected preschool precursor literacy skills to contribute significantly to reading accuracy approximately 1 year later [Dynia et al., 2017; Fricke et al., 2016; Murphy, Justice, O'Connell, Pentimonti, \& Kaderavek, 2016]. Finally, we expected all preschool precursor literacy variables to contribute significantly to the children's reading status in their first year of formal schooling [National Early Literacy Panel, 2008].

\section{Method}

Design

This study follows up our initial investigation of emergent literacy in preschool children with ASD [Westerveld et al., 2017] using a prospective cohort design. Ethics approval was granted by the Griffith University Human Research Ethics Committee (AHS/13/14/HREC) and the Sydney Children's Hospitals Network ethics committee (HREC/14/SCHN/270).

\section{Participants}

Participants included 41 children (35 male, 6 female) whose parents agreed to follow-up from the initial cohort of $57(72 \%)$. Those who declined participation reported change of location out of state $(n=3)$, being unavailable for assessment $(n=3)$, or challenges in child behaviors perceived to limit capacity to complete a test session $(n=2)$. Parents of two children did not provide reasons 
for declining participation, while those of six children were unable to be contacted by either phone or email. There were no significant group differences between the children whose parents did/did not agree to participate on baseline measures, including receptive vocabulary (Peabody Picture Vocabulary Test-Fourth Edition [PPVT4] SS) [Dunn \& Dunn, 2007] $t(1,55)=0.821, P=0.57$; autism severity (Social Communication Questionnaire [SCQ]) [Rutter, Bailey, \& Lord, 2003] $t(1,55)=0.083$, $P=0.93$; parent-reported communication skills (VABS-II Communication SS) [Sparrow, Cicchetti, \& Balla, 2005] $t(1,54)=0.406, P=0.67$; or developmental quotient (DQ; Mullen Scales of Early Learning [MSEL]) [Mullen, 1995] $t(1,54)=0.821, P=0.42$.

Inclusion criteria for the initial study [Westerveld et al., 2017] included (1) a verified diagnosis of ASD, which included a review of the initial community diagnosis, as well as further verification based on the Autism Diagnostic Observation Schedule (ADOS) [Lord et al., 2012] administered by trained professionals. The SCQ [Rutter et al., 2003] was used for those without an existing ADOS, using a cut-off score of 11 or higher $(n=33)$ [Eaves, Wingert, Ho, \& Mickelson, 2006]. For two children, the SCQ results were borderline and the ADOS was administered by a trained research assistant to verify diagnosis; (2) aged at least 48 months, prior to formal school entry; (3) verbal as shown through the ability to speak in short sentences; and (4) able to participate in preschool activities. Characteristics of participating children are shown in Table 1. All primary caregivers spoke English as their main language, although two caregivers reported

Table 1. Participant Characteristics at Time 1 (Preschool) and Time 2 (Year 1)

\begin{tabular}{lcccr}
\hline & $n$ & Mean & Range & SD \\
\hline Time 1 & & & & \\
Gender (M/F) & $35 / 6$ & & & \\
Age (months) & 41 & 57.6 & $49-70$ & 5.7 \\
DevtQuotient & 41 & 78.1 & $44-119$ & 20.6 \\
PPVT-SS & 41 & 78 & $64-127$ & 16.1 \\
SCQ & 41 & 15.8 & $5-32$ & 6.0 \\
LSK & 41 & 8.6 & $0-25$ & 8.9 \\
PA & 41 & 6.3 & $0-10$ & 4.2 \\
Name writing & 41 & 3.6 & $0-7$ & 2.5 \\
RAN-SS & 41 & 88.1 & $55-136$ & 25.2 \\
Digits & 41 & 89.0 & $28-139$ & 25.2 \\
& & & & \\
Time 2 & & & & \\
Gender (M/F) & $35 / 6$ & & & \\
Age (months) & 41 & 73.4 & $66-81$ & 4.5 \\
Months of schooling & 41 & 9.2 & $4-12$ & 2.0 \\
CELF-P2 CLS & 38 & 75.6 & $45-122$ & 20.5 \\
\hline
\end{tabular}

Note. PPVT, Peabody Picture Vocabulary Test; SCQ, Social Communication Questionnaire; LSK, Letter sound knowledge; PA, phonological awareness, RAN, rapid automatic naming; CELF-P2 CLS, Clinical Evaluation of Language Fundamentals-Preschool 2nd Edition, Core Language Score.

${ }^{\mathrm{a} S S}$ (scores between 85 and 115 are WNL). their child was exposed to another language at home. Mothers' education was used as a proxy for socioeconomic status (SES) with $32 \%$ of mothers having completed Year 12 (completion of high school in Australia), whereas $63 \%$ had completed further education post high school, with data unavailable for two mothers. At the time of the current study, all children had commenced their first year of schooling. In Australia, children must be 5 years of age in the year in which they enrol, with differing cut-off dates for individual states or territories, with the school year running from January to December.

\section{Procedure}

Assessment sessions were scheduled so that the children had completed between 6 and 12 months (2-4 school terms) of their first year of schooling, although one child had only completed 4 months of schooling because of scheduling issues. Children were seen for a one-off assessment session by one of four research assistants: three were certified practicing speech-language pathologists and one a psychology $\mathrm{PhD}$ candidate. Assessment sessions lasted approximately $2 \mathrm{hr}$ and took place in early childhood centers, University clinics, or in the children's homes, depending on parent preference. Although there was a set number of tasks for each session, the order of the tasks was left up to the research assistants to facilitate completion of the tasks and to ensure the children were given breaks when needed. All sessions were voice recorded to assist with scoring.

\section{Measures}

Time 1. Measures collected at Time 1 as part of our initial study [Westerveld et al., 2017] are summarized below. For further details on measures please refer to Westerveld et al. [2017]. For participant performance, please see Table 1 .

Autism symptoms: The SCQ [Rutter et al., 2003] was completed by the primary caregiver, and the total raw score was used as a measure of autism symptoms (max 40).

Receptive vocabulary: The PPVT-4 [Dunn \& Dunn, 2007] was used to assess receptive vocabulary. SSs were calculated and used for analysis.

Nonverbal cognition: The visual reception and fine motor subtests of the MSEL [Mullen, 1995] were administered. A DQ was calculated by dividing the child's average age-equivalent score across these two subtests by the child's age [see Bishop, Guthrie, Coffing, \& Lord, 2011].

Phonological awareness: The beginning sound awareness subtest from the Phonological Awareness Literacy Screening for Preschoolers (PALS-PreK) [Invernizzi, Sullivan, Meier, \& Swank, 2004] was administered. This test has been specifically designed for 4 -year-old children and 
shows acceptable criterion validity, predictive validity, and internal consistency [Invernizzi et al., 2004]. This developmentally appropriate task was selected as there are no well-validated tests for measuring emergent literacy skills in preschool children with ASD. The beginning sound awareness task comprised four practice items and eight test items (e.g., "What sound does ball start with?"). Raw scores were used for analysis (max 8).

Letter sound knowledge: The LSK subtest from the PALS-PreK was used. For this task, the child was asked to produce the sound for 26 letters of the alphabet, printed in random order on a white sheet of paper. Raw scores were used for analysis ( $\max 26)$.

Name writing: For this task (a subtest from the PALSPreK), children were asked to write their name on a blank piece of paper. Attempts were scored using a seven-point scale, from 0 (scribble) to 7 (correct name with no incorrect letters).

RAN: A subtest from the Woodcock Reading Mastery Tests-Revised [Woodcock, 1998] was administered to measure the child's ability to rapidly name (a) objects and (b) colors. SSs were computed and used for analysis. A SS of 55 was awarded to children who were unable to complete the task or who made too many errors $(n=7)$.

Phonological memory-Digit span: The Recall of Digits Forward subtest of the NEPSY-II, a developmental neuropsychological assessment [Korkman, Kirk, \& Kemp, 2007], was used to assess phonological memory. This test has been normed on children ages 2 years, 6 months to 17 years, 11 months and requires the child to repeat a sequence of digits presented orally and is a measure of the amount of information a child can hold in mind at one time. Ability scores were used for analysis.

Time 2. Additional measures collected at follow-up are detailed below.

Oral language: To characterize the sample, language abilities at Time 2 were assessed using the Core Language Subtests of the CELF-Preschool-2nd Edition (CELF-P2) [Wiig, Secord, \& Semel, 2004]: Sentence structure, word structure, and expressive vocabulary. The CELF-P2 provides a Core Language SS $(M=100, \mathrm{SD}=15)$. The CELF-P2 is age-normed from 3 years, 0 months to 6 years, 11 months. The manual reports excellent test-retest stability for the three subtests (ranging from 0.78 to 0.90 ). Internal Consistency Reliability Coefficients are high, ranging from 0.80 to 0.89 for children with typical development and from 0.88 to 0.92 for clinical groups of children with ASD or language disorders.

Passage reading ability: Passage level reading ability was assessed using the York Assessment of Reading for Comprehension (YARC) [Psychological Assessments Australia, 2012], passage reading subtest. When administering the task, children are presented with a beginner passage and asked to read the specified lines aloud while the assessor reads every other line. For example, in the beginner passage (Anna and the party), the examiner reads "Anna was excited because she was going to a party." The child is then asked to read "She went into the bedroom to put on her outfit." If children successfully complete the beginner passage (i.e., $<15$ errors), the child is presented with the next passage. Twenty children (49\%) were unable to either pass the beginner passage or read passage 1. As SSs can only be computed based on completion of two consecutive passages, the beginner passage ability score, based on the number of errors on the beginner passage, was used as a measure of passage reading ability. The beginner passage ability score range is $22-40$, with a score of 30 considered to be appropriate for a child aged 5 years, 7 months. For descriptive purposes, reading ability SSs $(M=100, \mathrm{SD}=15)$ were computed for the 21 participants who completed both passages. We specifically selected this test as it was normed on Australian students $(n=1,049)$ aged 5 years, 1 month to 13 years, 3 months, across Years $1-7$ of schooling. The manual reports reliability data (based on parallel forms) of 0.71 (Cronbach's $\alpha$ ) for the beginner passage and 0.81 for the Level 1 passage.

Single word reading: Single word reading was assessed using the Castles and Coltheart Test 2 [Castles et al., 2009]. This test was selected as it was normed on Australian students $(n>1,000)$ and uses regular (e.g., bed, long, mist), irregular (e.g., good, wolf, eye), and nonword (e.g., norf, gop, hest) stimuli to assess a child's whole word recognition and decoding abilities. Children are shown individual written words and asked to read each word aloud. The test ends when the child reaches the ceiling score of five incorrect items for each word type. The test is available in both paper and online formats. Two children refused to participate in this task. Using the online version of the test, raw scores for each item type are converted into $z$ scores for the child's age based on the normative data. As norms were only available for 6 years, 0 months onward, raw scores were used for analysis.

\section{Results}

\section{Data Screening}

For the YARC-reading ability measure, two children were unable to complete the task, whereas 18 children were unable to complete beyond the beginner passage. For the CELF-P2, three children were noncompliant for the assessment and thus obtained no score; available data were analyzed and list-wise deletion by analysis utilized. For the remaining variables $2.25 \%$ was missing, and analysis suggested it was missing completely at random with Little's MCAR $\chi^{2}(69)=76.56, P=0.25$. Data were thus deleted list wise by analysis as deemed acceptable under these conditions [Tabachnick \& Fidell, 2013]. 
Data were also screened for meeting assumptions of hierarchical multiple regression including independence of residuals (Durbin-Watson statistic of 1.59), multivariate outliers/influential data points, multicollinearity, normality of residuals, and homoscedasticity of residuals, with no major violations observed. Minor violations to homoscedasticity were observed; however, regression is robust to such violations and thus analysis was conducted without adjustment.

For the logistic regression (question three), linearity of the continuous variables with respect to the logit of the dependent variable was assessed via the Box-Tidwell procedure [Box \& Tidwell, 1962]. Based on this assessment, all continuous independent variables were found to be linearly related to the logit of the dependent variable. There was one studentized residual with a value of $Z>2.5$ and this case was removed from the logistic regression analysis. All variables were inspected for distribution. Shapiro-Wilk statistics showed that five variables were not normally distributed, including PPVT, LSK, PA, Name writing, and RAN. However, because log transformations were not considered appropriate, raw scores were used for analysis. Considering the exploratory nature of the study, we used a backward-selection method when performing the logistic regression.

\section{Reading Ability}

We first wanted to describe our sample of participants on two measures of reading ability: single word reading ability and passage reading ability. There was wide variability in performance, with regular single word reading scores ranging from 0 to 35 . As shown in Table 2, only 21 of the

Table 2. Reading Accuracy-Related Measures at Year 1 of schooling (Time 2 Assessment)

\begin{tabular}{|c|c|c|c|c|c|}
\hline & $n$ & Mean (SD) & Range & Skewness & Kurtosis \\
\hline $\begin{array}{r}\mathrm{CC}-2 \text { regular } \\
\text { word } \\
\text { reading }\end{array}$ & 39 & $9.54(11.60)$ & $0-35$ & 0.982 & -0.531 \\
\hline $\begin{array}{r}\text { CC-2 } \\
\text { irregular } \\
\text { word } \\
\text { reading }\end{array}$ & 39 & $5.64(6.80)$ & $0-23$ & 0.907 & -0.483 \\
\hline $\begin{array}{r}\mathrm{CC}-2 \\
\text { nonword } \\
\text { reading }\end{array}$ & 39 & $5.97(8.95)$ & $0-35$ & $1.710 *$ & 2.263 \\
\hline $\begin{array}{r}\text { YARC } \\
\text { beginner } \\
\text { passage } \\
\text { ability } \\
\text { score }\end{array}$ & 39 & $29.23(7.41)$ & $22-40$ & 0.430 & -1.554 \\
\hline $\begin{array}{r}\text { YARC reading } \\
\text { ability } \\
(\mathrm{SS})\end{array}$ & 21 & $102.95(17.33)$ & $74-130$ & 0.367 & -0.694 \\
\hline
\end{tabular}

Note. CC-2, Castles and Coltheart, $2^{\text {nd }}$ Edition; YARC, York Assessment of Reading for Comprehension.

*Significant skewness $(P<0.01)$.
41 children were able to read both the beginner passage and passage 1 required to obtain a SS on reading ability on the YARC. Two children were unable to complete this task altogether. Passage reading ability (SS) for the 21 children who were able to complete both the beginner passage and passage 1 was highly correlated with single word regular reading $(r=0.90, P<0.001)$. Finally, we calculated the correlations between regular single word reading ability and age at Time 2 assessment ( $r=0.09, P=0.57)$, and regular single word reading and time spent at school ( $r=0.12 P=0.49$ ). As these were not significant, age at Time 2 and time spent at school were excluded from further analysis.

Single word reading included three subscales, nonword, regular, and irregular. As shown in Table 2, floor effects were found for nonword reading, shown through significant skew $(z=4.52)$ and kurtosis $(z=3.05)$ statistics; regular and irregular word reading were highly correlated ( $r=0.93, P<0.001)$; therefore, regular word reading was selected as the outcome for single word reading ability. Finally, single word reading was highly correlated with beginner passage ability score $(r=0.92, P<0.001)$ and showed a similar pattern of significant correlations with other measures (see Table 3). As such we decided to focus on single regular word reading only for research question one (preschool predictors of word reading ability in year one of schooling).

\section{Emergent Literacy Predictors}

As shown in Table 3, the only variable at Time 1 that was not related to reading ability at Time 2 was autism symptoms (SCQ). This measure was consequently excluded from further analysis. All other preschool variables were significantly related to Year 1 single word, and passagereading ability outcomes, with correlations ranging from 0.41 to 0.71 .

We examined longitudinal predictors of single word reading ability in Year 1, and conducted hierarchical multiple regression analyses. At Step 1, nonverbal cognition (DQ, $\beta=0.45, t=3.05, P=0.004$ ) was entered as a control variable and accounted for a significant $17.9 \%$ (adjusted $R^{2}$ ) of the variance in single word reading, $F(1,37)=9.31$, $P=0.004$. At Step 2, vocabulary (PPVT SS, $\beta=0.15$, $\left.t=0.70, P=0.49, s r^{2}=0.0064\right)$, and the precursor literacy variables (LSK, $\beta=0.51, t=2.70, P=0.01, s r^{2}=0.094$; PA, $\beta=0.07, t=0.44, p=0.67, s r^{2}=0.0025$; name writing, $\beta=0.10, t=0.64, P=0.53, s r^{2}=0.0053 ; \mathrm{RAN}, \beta=0.12$, $t=0.78, P=0.44, s r^{2}=0.0079$; Digit span, $\beta=-0.08$, $t=0.46, P=0.65, s r^{2}=0.0028$ ) were entered and added an additional $32.6 \%$ (adjusted $R^{2}$ ) of the variance $F$ $(6,31)=5.05, P=0.001$. We subsequently removed individual variables (from Step 2) that contributed a nonsignificant (all $P>0.2$ ) proportion of the variance, leaving only LSK in the model $(P=0.01)$. The final model 
Table 3. Correlations Between Preschool (Time 1) Variables and Time 2 Reading Ability Outcomes

\begin{tabular}{|c|c|c|c|c|c|c|c|c|c|c|}
\hline & SCQ & PPVT & DevtQuotient & LSK & PA & NW & RAN & Digits & RWreading & YARCbeg \\
\hline SCQ & - & 0.02 & 0.03 & -0.07 & -0.05 & 0.02 & -0.17 & 0.02 & 0.05 & -0.01 \\
\hline PPVT & & & $0.72 * *$ & 0.30 & $0.45 * *$ & $0.49 * *$ & $0.40 *$ & $0.60 * *$ & $0.45 * *$ & $0.51 * *$ \\
\hline DevtQuotient & & & - & $0.32 *$ & 0.20 & $0.48 * *$ & $0.38 *$ & $0.55^{* *}$ & $0.45 * *$ & $0.50 * *$ \\
\hline LSK & & & & - & $0.63 * *$ & $0.47 * *$ & $0.57 * *$ & $0.45 * *$ & $0.71 * *$ & $0.73 * *$ \\
\hline PA & & & & & - & $0.38 *$ & $0.34 *$ & $0.38 *$ & $0.53 * *$ & $0.49 * *$ \\
\hline Name writing & & & & & & - & 0.30 & $0.57 * *$ & $0.50 * *$ & $0.56 * *$ \\
\hline RAN & & & & & & & - & 0.29 & $0.53 * *$ & $0.54 * *$ \\
\hline Digits & & & & & & & & - & $0.41 * *$ & $0.45 * *$ \\
\hline RWReading & & & & & & & & & - & $0.92 * *$ \\
\hline YARCbeg & & & & & & & & & & - \\
\hline
\end{tabular}

Note. SCQ, Social Communication Questionnaire; PPVT, Peabody Picture Vocabulary Test; LSK, letter sound knowledge; PA, phonological awareness; NW, name writing; RAN, rapid automatic naming; Digits, digit span; RWreading, regular word reading; YARCbeg, beginner passage ability score on the York Assessment of Reading for Comprehension.

$* P<0.05$ level.

$* * P<0.01$ level.

including DQ and LSK was statistically significant, $F(2,36)=22.80, P<0.001$, adjusted $R^{2}=0.534$, accounting for $53.4 \%$ of the variance in single word reading ability. Variables in this model included DQ $(\beta=0.24$, $t=2.00, P=0.053)$ and $\operatorname{LSK}(\beta=0.64, t=5.40, P<0.001)$. The addition of LSK to DQ resulted in a statistically significant increase of $35.5 \%$ (adjusted $R^{2}$ ) of the variance in single word reading, $F(1,36)=29.21, P<0.001$.

\section{Prediction of Group Membership}

To answer research question two, we investigated preschool group differences in nonverbal cognition, vocabulary, and precursor literacy skills. As reported in the data screening section, one case was removed for analysis based on the studentized residual, leaving 40 cases for this part of the analysis. Children who scored within the normal range $(\mathrm{SS}>85)$ on the YARC reading accuracy (passage reading ability) were considered average readers $(n=17)$, whereas children who scored below SS85 or who could not complete the beginner passage $(n=2)$ were categorized as "below average" readers (total $n=23$ ). We conducted independent $t$ tests (with Bonferroni adjustment for multiple comparisons) and adjustment for heterogeneity of variance when needed (LSK, PA, and RAN). As shown in Table 4, the average readers performed significantly better on all tasks compared to the below average readers. There were no group differences in autism severity (SCQ; $P=0.551$ ), nor age at follow up $(P=0.379)$, or time spent at school $(P=0.932)$.

To answer research question three, a binomial logistic regression was performed to determine if we could predict reading group membership in Year 1 using preschool variables (PPVT-SS, DQ, LSK, PA, Name writing, RAN, and Digit span). We did not include SCQ, based on the results of the independent $t$ tests. Consistent with the exploratory nature of our analysis, all variables of interest were initially entered into the logistic model and nonsignificant terms $(P>0.10)$ removed using backward conditional elimination. Only three of the variables remained significant, PPVT-SS, Name writing, and RAN. The nonsignificant predictors were removed, and the logistic analysis was rerun entering PPVT-SS, Name writing, and RAN. Table 5 shows the results of the final model. Note that the log likelihood changed from 16.41 at Step 1 to 17.76 at Step 5 and that the Hosmer and Lemeshow goodness of fit test was nonsignificant $(P=0.73)$, indicating the model is not a poor fit. The model was statistically significant, $\chi^{2}(3)=38.79, P<.001$.

Table 4. Group Comparisons of Average $(n=17)$ Versus Below Average Readers $(n=23)$ on Preschool Measures

\begin{tabular}{|c|c|c|c|c|c|}
\hline & $\begin{array}{l}\text { Average } \\
\text { readers }\end{array}$ & $\begin{array}{l}\text { Below } \\
\text { average } \\
\text { readers }\end{array}$ & & & \\
\hline Variable & $\begin{array}{l}\text { Mean (SD) } \\
\text { range }\end{array}$ & $\begin{array}{l}\text { Mean (SD) } \\
\text { range }\end{array}$ & $t$ & $P$ & $\begin{array}{c}\text { Cohen's } \\
\quad d\end{array}$ \\
\hline SCQ & $\begin{array}{c}16.6(6.4) \\
7-32\end{array}$ & $\begin{array}{c}15.5(5.8) \\
5-28\end{array}$ & .601 & 0.551 & 0.18 \\
\hline DQ & $\begin{array}{c}89.1(16.6) \\
65-119\end{array}$ & $\begin{array}{c}68.7(18.5) \\
44-108\end{array}$ & 3.618 & 0.001 & 1.16 \\
\hline PPVT-SS & $\begin{array}{c}99.4(13.7) \\
76-124\end{array}$ & $\begin{array}{c}80.1(10.0) \\
64-102\end{array}$ & 5.142 & $<0.001$ & 1.61 \\
\hline LSK & $\begin{array}{c}15.1(9.0) \\
0-25\end{array}$ & $\begin{array}{c}3.7(5.2) \\
0-20\end{array}$ & 4.700 & $<0.001$ & 1.55 \\
\hline PA & $\begin{array}{c}9.1(2.1) \\
0-10\end{array}$ & $\begin{array}{c}4.2(4.0) \\
0-10\end{array}$ & 4.749 & $<0.001$ & 1.53 \\
\hline NW & $\begin{array}{c}5.1(2.1) \\
1-7\end{array}$ & $\begin{array}{c}2.3(2.1) \\
1-7\end{array}$ & 4.148 & $<0.001$ & 1.33 \\
\hline RAN-SS & $\begin{array}{c}104.7(18.1) \\
64-136\end{array}$ & $\begin{array}{c}75.7(18.6) \\
55-119\end{array}$ & 4.920 & $<0.001$ & 1.58 \\
\hline Digits & $\begin{array}{c}103.3(22.4) \\
62-139\end{array}$ & $\begin{array}{c}77.3(22.4) \\
28-120\end{array}$ & 3.715 & 0.001 & 1.16 \\
\hline
\end{tabular}

Note. SCQ, Social Communication Questionnaire; DQ, developmental quotient; PPVT, Peabody Picture Vocabulary Test; LSK, letter sound knowledge; PA, phonological awareness; NW, name writing; RAN, rapid automatic naming; Digits, digit span, ability score; SS, standard score. 
Table 5. Logistic Regression for Year One Reading Accuracy Status on the YARC (Final Model)

\begin{tabular}{|c|c|c|c|c|c|c|c|}
\hline Step & Variable & Coefficient & SE & Wald & $P$ & Odds ratio & 95\% C.I. \\
\hline \multirow[t]{4}{*}{5} & Constant & -23.129 & 8.195 & 7.965 & 0.005 & 0.000 & \\
\hline & PPVTSS & 0.125 & 0.059 & 4.500 & 0.034 & 1.134 & $1.010-1.273$ \\
\hline & NW & 0.821 & 0.381 & 4.657 & 0.031 & 2.274 & $1.078-4.793$ \\
\hline & RANSS & 0.095 & 0.038 & 6.266 & 0.012 & 1.100 & $1.021-1.185$ \\
\hline
\end{tabular}

Note. PPVT, Peabody Picture Vocabulary Test; NW, name writing; RAN, rapid automatic naming; SS, standard score.

The model explained $80.8 \%$ (Nagelkerke $R^{2}$ ) of the variance in reading group membership and correctly classified $92.5 \%$ of cases. Furthermore, sensitivity of the model (how well the model predicted which children would end up in the average reader group) was high (94.1\%), and so was specificity (how well the model predicted which children would end up as below average readers) at $91.3 \%$.

\section{Discussion}

The present study investigated the preschool predictors of reading ability in a group of children with ASD who were in their first year of schooling. The findings of our initial study [Westerveld et al., 2017] indicated early strengths in print-related emergent literacy skills in a group of verbal preschoolers with ASD, including alphabet knowledge and PA, but noted wide variability in performance consistent with previous investigations [e.g., Lanter, Watson, Erickson, \& Freeman, 2012]. The current study tracked this cohort of children, who participated in a battery of reading tasks when they had completed between 4 and 12 months of formal education. We were able to predict $53.4 \%$ of the variance in regular single-word reading ability when entering nonverbal cognition at Step 1, and adding preschool LSK at Step 2. Our results further revealed that approximately $50 \%$ of this group of participants showed difficulties in reading on a standardized test of passage reading ability. Finally, group membership (average vs. below average readers on passage reading ability at the end of their first year of schooling) could be predicted with $92.5 \%$ accuracy based on preschool performance in vocabulary, name writing, and RAN. These results advance our understanding of the early reading pathways of a group of children with ASD who were initially assessed prior to school entry.

The group of children participated in two tasks of reading ability: single word reading and passage reading. Although we measured single word reading across nonwords, irregular words, and regular words, significant floor effects were found for nonword reading, with 19 children unable to obtain a score on this task. Based on strong correlations between regular and irregular word reading ability scores, we selected regular word reading as our outcome measure for word reading ability in subsequent analyses. At this early stage of formal schooling, we also found strong correlations between regular single word reading and beginner passage reading, indicating both tasks tapped into a similar skill (i.e., the ability to read single words). We found wide variability across both reading measures, ranging from 0 to maximum in single word reading and from very low to average range in beginner passage-reading ability relative to their age and stage of schooling. Finally, a subset of children showed performance within normal limits on the standardized test of passage-reading ability, however approximately half showed significant challenges, with 20 children unable to complete the standardized passage reading task. This finding is in line with results found in previous research, showing wide variation in performance in reading ability in school-age children with ASD, as well as up to $50 \%$ displaying challenges [e.g., Arciuli et al., 2013; Nation et al., 2006].

Our first research question asked which preschool variables including nonverbal cognition, vocabulary, and precursor literacy skills predicted word reading ability during the first year of formal schooling. We found nonverbal cognition predicted a significant proportion of the variance $(17.9 \%)$ in regular single word reading ability. These results are consistent with results from previous studies confirming the important correlations between nonverbal cognition and reading ability in both typically developing children and in children with ASD [Catts, Herrera, Nielsen, \& Bridges, 2015; Davidson \& Ellis Weismer, 2014; Lanter et al., 2012; Nation \& Snowling, 2004]. Our results further showed that LSK was the only significant independent predictor, once nonverbal cognition was entered into the model. Together, nonverbal cognition and preschool LSK accounted for $53.4 \%$ of the variance in regular word reading ability at the end of the first year of schooling. Closer inspection of children's performance on the precursor literacy skills (Table 3) shows moderate correlations between LSK, PA, RAN, and digit span, which may explain why some of these skills did not emerge as significant in our model. However, the strength of these correlations are very similar to those found in studies of typically developing children [Catts et al., 2015], and confirm the importance of LSK during the preschool years in explaining variance in early reading outcomes [Fricke et al., 2016; National Early Literacy 
Panel, 2008]. LSK is often regarded as an indication of children's emerging understanding of the symbolic nature of written language, explaining the causal relationship between preschool letter knowledge and later reading skills in typically developing children. Our results show the same causal relationship may apply for young children with ASD, who as a group often show early strengths in letter knowledge [Davidson \& Ellis Weismer, 2014; Dynia, Lawton, Logan, \& Justice, 2014]. The most likely explanation for the often superior letter name or sound knowledge in preschoolers with ASD compared to their peers, includes a detail-focused style of cognitive processing [Happé \& Frith, 2006]. Based on our results, this early repeated focus on letters may well lead to better single word reading skills in children with ASD.

Although our results are in line with previous research into preschool predictors of early word reading in children with autism conducted by Dynia et al. [2017], we were able to explain much more of the variance (i.e., 54.3\% vs. 18.63\%). Notably, Dynia et al. found that the only individual significant predictor of first grade decoding ability was preschool PA, accounting for $4 \%$ of the variance. In contrast, in the current study, PA (beginning sound awareness) was not a significant individual predictor and instead LSK predicted $35.5 \%$ of the variance. It should be noted that Dynia et al. [2017] only considered PA, print concepts, and letter name knowledge in their regression model, used a more advanced PA task (elision and blending of sounds), and did not account for nonverbal cognition or receptive vocabulary. Considering nonverbal cognition is a strong indicator of early reading performance in children with ASD, it is important to consider cognition as a variable of interest [e.g., Davidson \& Ellis Weismer, 2014]. It should also be stated that Dynia et al. [2017] used a nonword reading task as the outcome measure, as opposed to a regular word reading task as was used in the current study. Nonword reading requires the child to apply phonological decoding strategies (i.e., utilizing PA and alphabet knowledge), which may explain why PA was a significant predictor in Dynia et al.'s [2017] study. Previous research suggests that some children with ASD may have particular difficulty decoding nonwords [Henderson et al., 2014; Nation et al., 2006], whereas other studies have found nonword reading to be intact in school-age children with ASD, most of whom showed nonverbal cognitive abilities within the typical range [Gabig, 2010; McIntyre, Solari, Gonzales, et al., 2017]. Although we measured nonword reading in the current study, significant floor effects were found, with 19 children unable to read any nonwords. These floor effects may indicate early weaknesses in nonword reading and future research should closely monitor the early word-reading development of children with ASD (including those with cognitive impairment) across nonwords, regular words, and irregular words, to better understand strengths and weaknesses in utilizing phonological and non-phonological decoding strategies.

Second, we investigated if preschool cognitive, oral language, and precursor literacy skills differed between average or below average readers in their first year of formal schooling. We divided children into average versus below average groups based on their performance on the standardized passage reading task as this was considered the most ecologically valid measure of real-world reading skills applicable to the classroom. As shown in Table 4, as a group, children who were reading in the average range scored significantly higher across all preschool precursor literacy measures as well as vocabulary and nonverbal cognition, with large effect sizes, but showed no significant differences in the number of autism symptoms. These findings are consistent with prospective studies with children with language disorder [e.g., Murphy et al., 2016] and suggest the early literacy profiles of children with ASD may reflect the children's challenges with language learning more broadly. It should be noted, however, that ranges in scores overlap between the two reader groups, indicating that these two groups were not distinct samples.

Third, we explored if preschool oral language and precursor literacy performance can predict whether students will show average or below average performance on a standardized passage-reading task in their first year of formal schooling. The final model, containing vocabulary, name writing, and RAN together, predicted group membership, explaining $80.8 \%$ of the variance. Furthermore, the model showed high sensitivity (94.1\%) and specificity $(91.3 \%)$, accurately classifying $92.5 \%$ of the children. Our findings differed significantly from those reported by Murphy et al. [2016], who utilized a similar design to investigate preschool predictors of word reading ability (using a nonword reading task) in kindergarten-age children with identified language disorders, 20\% of whom had comorbid disabilities such as ASD or Down syndrome. In summary, Murphy et al.'s results indicated that measures of oral language, alphabet knowledge, and print concept knowledge were significant unique predictors, combined explaining $31.1 \%$ of the variance. Moreover, although specificity was high (92.6\%), sensitivity was low at a regular $50 \%$ probability value $(63.3 \%)$. There are several likely explanations regarding the differences in findings between the two studies, including children's ASD status and the reading outcome measure that was used. Our study utilized a passage-level reading task (which was highly correlated to the children's regular word reading), as opposed to a nonword reading task, performance on which will arguably be influenced by different precursor literacy skills [Shapiro, Carroll, \& Solity, 2013]. Moreover, the percentage of children identified with early reading difficulties in Murphy et al. [2016] was noticeably low compared to previous research investigating early reading 
skills of children with identified language disorders [e.g., Catts, Fey, Tomblin, \& Zhang, 2002]. Therefore, their sample of children, some of whom presented with comorbid disabilities, all of whom attended early childhood special education classrooms, may simply not be representative of the wider population.

The results from our study clearly demonstrated the importance of preschool proficiency on measures of vocabulary, RAN, and name writing for predicting year one passage-reading ability in children with ASD. Vocabulary knowledge as measured by the PPVT is a good proxy for oral language skills and oral language ability is known to significantly influence early word reading ability in typically developing children and children at risk for reading disability [Catts, McIlraith, Bridges, \& Nielsen, 2017; Storch \& Whitehurst, 2002]. Name writing may reflect the child's interest in literacy and their understanding of the symbolic nature of written language and is also a known predictor of reading development, even after correcting for IQ or SES [National Early Literacy Panel, 2008]. Our study adds to our existing knowledge of the early literacy pathways of children with ASD by demonstrating the important contribution of RAN for predicting group membership of average versus below average readers. Consistent with results from previous studies investigating the contribution of RAN to early word reading ability [Bishop et al., 2009; Catts et al., 2017], our results showed that a weakness in RAN may be an important risk factor for later reading difficulties in preschoolers with ASD.

The fact that LSK did not feature in our final model predicting group membership was unexpected and seems to contradict previous research findings [Dynia et al., 2017; Murphy et al., 2016]. Considering the strong correlations between LSK and other variables, the most likely explanation is that LSK was suppressed by other variables (RAN, name writing) in our final model. Regardless, preschool LSK was a powerful predictor of regular single word reading, highlighting the importance of assessing this skill and monitoring its development during the transition to school.

\section{Implications}

The results from our study reveal the possibility of identifying children with ASD who are at risk of early reading difficulties, prior to school entry. Children's performance on a short battery of tasks measuring vocabulary, name writing, and RAN correctly predicted group membership (average or below) for $92.5 \%$ of children on a standardized passage-reading task more than one year later, during their first year of formal schooling. These results are highly relevant considering more than $50 \%$ of the verbal preschoolers in this cohort may be considered at risk of persistent reading accuracy difficulties very early in their school career and thus provide the opportunity for tailored interventions.

Although three main variables predicted early passagelevel reading skills in young school-age children with ASD, our results showed moderate correlations between all precursor literacy skills, and therefore suggest assessment may take a variety of forms linked to children's strengths and needs. Considering most tasks were short and easy to administer to preschoolers with ASD [see Westerveld et al., 2017], there is a potential for screening by educators and staff (e.g., childcare, early childhood learning staff) without the need for extensive training. Based on our findings, there is an urgent need for early intervention beyond autism symptoms and challenging behavior that have been the major focus in research [Mottron, 2017], to target pre-academic skills to support better school outcomes with challenges experienced by the majority of school students [Australian Bureau of Statistics, 2014; Keen, Webster, \& Ridley, 2015].

\section{Limitations and Future Directions}

Several limitations should be considered in interpreting these results. First, the study focused on verbal preschoolers with ASD, whereas there is evidence to suggest that as many as 30\% of children exiting early intervention programs remain minimally verbal [Rose, Trembath, Keen, \& Paynter, 2016]. Understanding the literacy needs of these children is a challenge for future research with a clear need to develop valid measures to assess skills in this group [Koppenhaver \& Erickson, 2003]. Unfortunately, we retained only $72 \%$ of our initial cohort for this followup study. However, the current group $(n=41)$ matched the initial group on measures of autism symptoms, oral language, and precursor literacy skills, so we are confident these results reflect the larger cohort. Furthermore, although the sample size was relatively small, effect sizes were large, and indicate our findings are robust. The cohort of children in our study was from families with relatively high SES, and parents and caregivers showed an interest in literacy by signing up for the study. Future research should attempt to recruit a group of participants from a broader range of backgrounds. At Time 1, we did not assess whether the children were able to read, nor did we ask the parents. Future research should take into consideration that some of these preschoolers might have been early readers.

To ensure optimum performance from the children, we did not control for task order during the assessment sessions, which may have influenced the results. Furthermore, a percentage of children was unable to complete some of the measures, including the RAN task ( 7 children), and the standardized passage reading task (20 children). Recent research has shown the important correlations between task-focused behavior and presence or absence of 
reading difficulties in children at risk of reading disorders [Eklund, Torppa, \& Lyytinen, 2013]. Although we were able to correctly predict $92.5 \%$ of group membership using an evidence based battery of preschool measures [National Early Literacy Panel, 2008], future research should include measures of engagement, which in children with ASD, may be linked to their specific interests [e.g., see Keen, 2009]. For the single word reading tasks, we used raw scores for analysis, and without a control group of typically developing children we cannot conclude how the children with ASD performed compared to their peers. However, finding suitable tasks for young children with ASD is a challenge and we believe we obtained reliable results due to generally good attention and compliance to the tasks selected. We need to interpret our results with caution as early success in reading short passages does not guarantee these children will become accurate and fluent readers. Following these children longitudinally is clearly needed to further understand these children's reading trajectories. Finally, intervention research is needed to determine pathways to reading success and to establish the nature of the relationship between precursor literacy skills (e.g., causal, necessary but not sufficient, or linked to other variables such as oral language) and later reading.

\section{Conclusion}

The findings of this study further elucidate the nature of reading strengths and difficulties in young verbal children with ASD. Despite the common notion that children with ASD show strengths in reading accuracy, almost half of our community sample of participants showed early signs of passage reading difficulties, reinforcing the need for timely and accurate assessment of their early reading skills [Paynter, Westerveld, \& Trembath, 2016]. Importantly, although nonverbal cognition was strongly linked to single word reading, children's LSK added significantly to the variance. Furthermore, at group-level, children who showed satisfactory passage reading ability in their first year of schooling, performed stronger on all preschool precursor literacy variables, with vocabulary, name writing ability, and RAN predicting group membership with a high degree of precision. Thus, while further research examining the nature of reading strengths and difficulties in children with ASD is certainly warranted, particularly in minimally verbal children, the initial targets for early intervention appear to be well defined.

\section{Acknowledgments}

The authors sincerely thank the families who participated in this study for their time and commitment to the study.
The authors acknowledge the financial support of the Cooperative Research Centre for Living with Autism, established and supported under the Australian Government's Cooperative Research Centres Program. David Trembath is supported by a National Health and Medical Research Council ECR Fellowship [GNT1071881]. The authors declare they have no conflicts of interest. The authors acknowledge the statistical support provided by Justin Scott, Institute of Molecular Biology, University of Queensland.

\section{References}

Arciuli, J., Stevens, K., Trembath, D., \& Simpson, I. C. (2013). The relationship between parent report of adaptive behavior and direct assessment of reading ability in children with Autism Spectrum Disorder. Journal of Speech, Language, and Hearing Research, 56(6), 1837-1844. https://doi.org/10. 1044/1092-4388(2013/12-0034)

Australian Bureau of Statistics (Producer). (2014). Autism in Australia. Retrieved from http://www.abs.gov.au/AUSSTATS/ abs@.nsf/Latestproducts/4428.0Main\%20Features12012?opend ocument\&tabname $=$ Summary\&prodno $=4428$.0\&issue $=2012 \&$ num $=\& v i e w=$

Bishop, D. V. M., McDonald, D., Bird, S., \& Hayiou-Thomas, M. E. (2009). Children who read words accurately despite language impairment: Who are they and how do they do it? Child Development, 80(2), 593-605. https://doi.org/10.1111/j.1467-8624. 2009.01281.x

Bishop, S. L., Guthrie, W., Coffing, M., \& Lord, C. (2011). Convergent validity of the Mullen scales of early learning and the differential ability scales in children with autism spectrum disorders. American Journal on Intellectual and Developmental Disabilities, 116(5), 331-343. https://doi.org/10. 1352/1944-7558-116.5.331

Box, G. E., \& Tidwell, P. W. (1962). Transformation of the independent variables. Technometrics, 4(4), 531-550

Brown, H. M., Oram-Cardy, J., \& Johnson, A. (2013). A meta-analysis of the reading comprehension skills of individuals on the autism spectrum. Journal of Autism and Developmental Disorders, 43(4), 932-955. https://doi.org/10.1007/ s10803-012-1638-1

Cabell, S. Q., Justice, L. M., Zucker, T. A., \& McGinty, A. S. (2009). Emergent name-writing abilities of preschool-age children with language impairment. Language, Speech, and Hearing Services in Schools, 40, 53-66

Castles, A., Coltheart, M., Larsen, L., Jones, P., Saunders, S., \& McArthur, G. M. (2009). Assessing the basic components of reading: A revision of the Castles and Coltheart test with new norms (CC2). Retrieved from www.motif.org.au

Catts, H. W., Fey, M. E., Tomblin, J. B., \& Zhang, X. (2002). A longitudinal investigation of reading outcomes in children with language impairments. Journal of Speech, Language, and Hearing Research, 45(6), 1142-1157

Catts, H. W., Herrera, S., Nielsen, D. C., \& Bridges, M. S. (2015). Early prediction of reading comprehension within the simple view framework. Reading and Writing: An 
Interdisciplinary Journal, 28, 1407-1425. https://doi.org/10. 1007/s11145-015-9576-X

Catts, H. W., McIlraith, A., Bridges, M. S., \& Nielsen, D. C. (2017). Viewing a phonological deficit within a multifactorial model of dyslexia. Reading and Writing, 30, 613-629. https://doi.org/10.1007/s11145-016-9692-2

Chall, J. S. (1983). Learning to read: The great debate (updated). New York: McGraw-Hill

Davidson, M. M., \& Ellis Weismer, S. (2014). Characterization and prediction of early reading abilities in children on the autism spectrum. Journal of Autism and Developmental Disorders, 24(4), 828-845. https://doi.org/10.1007/s10803-013-1936-2

Dunn, L. M., \& Dunn, D. M. (2007). Peabody picture vocabulary test - 4. Circle Pines, MN: American Guidance Service

Dynia, J. M., Brock, M. E., Justice, L. M., \& Kaderavek, J. N. (2017). Predictors of decoding for children with autism spectrum disorder in comparison to their peers. Research in Autism Spectrum Disorders, 37, 41-48

Dynia, J. M., Lawton, K., Logan, J. A. R., \& Justice, L. M. (2014). Comparing emergent-literacy skills and home-literacy environment of children with autism and their peers. Topics in Early Childhood Special Education, 34(3), 142-153. https:// doi.org/10.1177/0271121414536784

Eaves, L., Wingert, H. D., Ho, H., \& Mickelson, E. C. (2006). Screening for autism spectrum disorders with the social communication questionnaire. Journal of Developmental and Behavioral Pediatrics, 27(suppl. 2), s95-s103. https://doi. org/10.1097/00004703-200604002-00007

Eklund, K. M., Torppa, M., \& Lyytinen, H. (2013). Predicting reading disability: Early cognitive risk and protective factors. Dyslexia, 19(1), 1-10. https://doi.org/10.1002/dys.1447

Fricke, S., Szczerbinski, M., Fox-Boyer, A., \& Stackhouse, J. (2016). Preschool predictors of early literacy acquisition in German-speaking children. Reading Research Quarterly, 51(1), 29-53. https://doi.org/10.1002/rrq.116

Gabig, C. S. (2010). Phonological awareness and word recognition in reading by children with autism. Communication Disorders Quarterly, 31(2), 67-85

Gillon, G. T. (2018). Phonological awareness: From research to practice (2nd ed.). New York: The Guilford Press

Happé, F., \& Frith, U. (2006). The weak coherence account: Detail-focused cognitive style in autism spectrum disorders. Journal of Autism and Developmental Disorders, 36(1), 5-25. https://doi.org/10.1007/s10803-005-0039-0

Henderson, L. M., Clarke, P. J., \& Snowling, M. J. (2014). Reading comprehension impairments in Autism Spectrum Disorders. L'Année Psychologique, 114(04), 779-797. https://doi. org/10.4074/S0003503314004084

Huemer, S. V., \& Mann, V. (2010). A comprehensive profile of decoding and comprehension in Autism Spectrum Disorders. Journal of Autism and Developmental Disorders, 40(4), 485-493. https://doi.org/10.1007/s10803-009-0892-3

Invernizzi, M., Sullivan, A., Meier, J. D., \& Swank, L. (2004). Phonological awareness literacy screening for preschoolers. Teacher's manual. Charlottesville: University of Virginia

Jacobs, D. W., \& Richdale, A. L. (2013). Predicting literacy in children with a high-functioning autism spectrum disorder. Research in Developmental Disabilities, 34(8), 2379-2390. https://doi.org/10.1016/j.ridd.2013.04.007
Keen, D. (2009). Engagement of children with autism in learning. Australasian Journal of Special Education, 33(2), 130-140. https://doi.org/10.1375/ajse.33.2.130

Keen, D., Webster, A., \& Ridley, G. (2015). How well are children with autism spectrum disorder doing academically at school? An overview of the literature. Autism, 20, 276-294. https:// doi.org/10.1177/1362361315580962

Koppenhaver, D. A., \& Erickson, K. A. (2003). Natural emergent literacy supports for preschoolers with autism and severe communication impairments. Topics in Language Disorders, 23(4), 283-292

Korkman, M., Kirk, U., \& Kemp, S. (2007). NEPSY-II: Clinical and interpretive manual. San Antonio, TX: Harcourt Assessment

Lanter, E., Watson, L. R., Erickson, K. A., \& Freeman, D. (2012). Emergent literacy in children with Autism: An exploration of developmental and contextual dynamic processes. Language Speech and Hearing Services in Schools, 43(3), 308-324. https://doi.org/10.1044/0161-1461(2012/10-0083)

Lindgren, K. A., Folstein, S. E., Tomblin, J. B., \& Tager-Flusberg, H. (2009). Language and reading abilities of children with autism spectrum disorders and specific language impairment and their first-degree relatives. Autism Research, 2(1), 22-38. https://doi. org/10.1002/aur.63

Lord, C., Rutter, M., DiLavore, P. C., Risi, S., Gotham, K., \& Bishop, S. (2012). Autism diagnostic observation schedule, second edition: ADOS-2. Torrance, CA: Western Psychological Services

McIntyre, N. S., Solari, E. J., Gonzales, J. E., Solomon, M., Lerro, L. E., Novotny, S., ... Mundy, P. C. (2017). The scope and nature of reading comprehension impairments in school-aged children with higher-functioning Autism Spectrum Disorder. Journal of Autism and Developmental Disorders, 47(9), 2838-2860. https://doi.org/10.1007/ s10803-017-3209-y

McIntyre, N. S., Solari, E. J., Grimm, R. P., Lerro, E., Gonzales, J. E., \& Mundy, P. C. (2017). A comprehensive examination of reading heterogeneity in students with high functioning autism: Distinct reading profiles and their relation to autism symptom severity. Journal of Autism and Developmental Disorders, 47(4), 1086-1101. https://doi. org/10.1007/s10803-017-3029-0

McNeill, B. C., Westerveld, M., Bysterveldt, A. v., Boyd, L., \& Gillon, G. (2013). Early name writing and invented-spelling development. New Zealand Journal of Educational Studies, 48(1), 50-65

Mottron, L. (2017). Should we change targets and methods of early intervention in autism, in favor of a strengths-based education? European Child \& Adolescent Psychiatry, 26(7), 815-825. https://doi.org/10.1007/s00787-017-0955-5

Mullen, E. M. (1995). Mullen scales of early learning. Circle Pines, MN: American Guidance Service

Murphy, K. A., Justice, L. M., O'Connell, A. A., Pentimonti, J. M., \& Kaderavek, J. N. (2016). Understanding risk for reading difficulties in children with language impairment. Journal of Speech, Language, and Hearing Research, 59, 1436-1447. https://doi. org/10.1044/2016_JSLHR-L-15-0110

Nation, K., Clarke, P., Wright, B., \& Williams, C. (2006). Patterns of reading ability in children with autism spectrum disorder. 
Journal of Autism and Developmental Disorders, 36(7), 911-919. https://doi.org/10.1007/s10803-006-0130-1

Nation, K., \& Snowling, M. J. (2004). Beyond phonological skills: Broader language skills contribute to the development of reading. Journal of Research in Reading, 27(4), 342-356

National Early Literacy Panel. (2008). Developing early literacy: Report of the national early literacy panel. Washington, DC: National Institute for Literacy

Norbury, C., \& Nation, K. (2011). Understanding variability in reading comprehension in adolescents with autism spectrum disorders: Interactions with language status and decoding skill. Scientific Studies of Reading, 15(3), 191-210. https:// doi.org/10.1080/10888431003623553

Paynter, J., Westerveld, M. F., \& Trembath, D. (2016). Reading assessment in children with autism spectrum disorder. Journal of Psychologists and Counsellors in Schools, 26(2), 205-217. https://doi.org/10.1017/jgc.2016.15

Psychological Assessments Australia. (2012). York Assessment of Reading for Comprehension (YARC), (Australian ed.): GL assessment. Sydney, NSW: Author.

Reid, D., Hresko, W., \& Hammill, D. (2001). Test of early reading ability (3rd ed.). Austin, TX: PRO-ED

Rose, V., Trembath, D., Keen, D., \& Paynter, J. (2016). The proportion of minimally verbal children with autism spectrum disorder in a community-based early intervention programme. Journal of Intellectual Disability Research, 60(5), 464-477. https://doi.org/10.1111/jir.12284

Rutter, M., Bailey, M. D., \& Lord, C. (2003). The Social Communication Questionnaire (SCQ). Los Angeles, CA: Western Psychological Services

Shapiro, L. R., Carroll, J. M., \& Solity, J. E. (2013). Separating the influences of prereading skills on early word and nonword reading. Journal of Experimental Child Psychology, 116(2), 278-295. https://doi.org/10.1016/j.jecp.2013.05.011

Sparks, R. L., Patton, J., \& Murdoch, A. (2014). Early reading success and its relationship to reading achievement and reading volume: Replication of '10 years later'. Reading and Writing, 27(1), 189-211. https://doi.org/10.1007/s11145-013-9439-2

Sparrow, S. S., Cicchetti, D. V., \& Balla, D. A. (2005). Vineland II: Vineland adaptive behavior scales. Bloomington, MN: Pearson

Storch, S. A., \& Whitehurst, G. J. (2002). Oral language and code-related precursors to reading: Evidence from a longitudinal structural model. Developmental Psychology, 38(6), 934-947. https://doi.org/10.1037/0012-1649.38.6.934

Tabachnick, B. G., \& Fidell, L. S. (2013). Using multivariate statistics (Vol. 6). Boston, MA: Pearson

Wagner, R. K., \& Torgesen, J. K. (1987). The nature of phonological processing and its causal role in the acquisition of reading skills. Psychological Bulletin, 101, 192-212

Wei, X., Christiano, E. R. A., Yu, J. W., Wagner, M., \& Spiker, D. (2015). Reading and math achievement profiles and longitudinal growth trajectories of children with an autism spectrum disorder. Autism, 19(2), 200-210. https://doi.org/10. $1177 / 1362361313516549$

Westerveld, M. F., Paynter, J., Trembath, D., Webster, A. A. Hodge, A. M., \& Roberts, J. (2017). The emergent literacy skills of preschool children with autism spectrum disorder. Journal of Autism and Developmental Disorders, 47(2), 424-438. https://doi.org/10.1007/s10803-016-2964-5

Wiig, E. H., Secord, W., \& Semel, E. (2004). Clinical evaluation of language fundamentals preschool - Second edition (CELF preschool-2). Toronto, Canada: The Psychological Corporation

Woodcock, R. W. (1998). Woodcock reading mastery tests-Revised. Circle Pines, MN: American Guidance Service 